\title{
0 futebol amador em Ponta Grossa/PR: uma análise da dimensão simbólica e instituinte do ritual de preparação para os jogos do Mirante Esporte Clube
}

\author{
The amateur football in Ponta Grossa/PR: \\ an analysis of the symbolic dimension and instituinte of the ritual \\ of preparation for the games of Mirante Esporte Clube
}

\author{
Miguel Archanjo de Freitas Junior \\ Universidade Estadual de Ponta Grossa (UEPG), Ponta Grossa/Brasil \\ Doutor em História, UFPR \\ mfreitasjr@uepg.br \\ Edilson de Oliveira \\ Universidade Estadual de Ponta Grossa (UEPG), Ponta Grossa/Brasil \\ Doutorando em Ciências Sociais Aplicadas, UEPG
}

\begin{abstract}
Resumo: A presente investigação etnográfica tem o objetivo de analisar a função simbólica e instituinte das ações que compõem o ritual de preparação dos jogadores do Mirante Esporte Clube, equipe de futebol pertencente ao campo futebolístico amador da cidade de Ponta Grossa, localizada no estado do Paraná-Brasil. No processo de aprendizagem e interpretação deste ritual, recorreu-se à etnografia, visto que o que se procura fazer em uma investigação etnográfica é compreender como os homens e mulheres tentam viver suas vidas. Para além da dimensão simbólica e espiritual do ritual, foi possível identificar ao longo do campeonato amador, que as ações executadas pelos jogadores contribuíam para a estruturação das posições sociais no grupo e no campo futebolístico amador pontagrossense. Deste modo, os atos do rito eram também atos de instituição, através dos quais alguém era notificado sobre a sua "nova" posição social.
\end{abstract}

Palavras-chave: Futebol amador; Etnografia; Cultura; Ritual; Poder simbólico.

Abstract: This ethnographic research aims at analyzing the symbolic and instituting function of the actions that make up the preparation ritual of Mirante E. C., a football team belonging to the amateur football field of the city of Ponta Grossa, located in the state of Paraná-Brazil. In the process of learning and interpreting this ritual, ethnography was used, since what one seeks to do in an ethnographic investigation is to understand how men and women try to live their lives. In addition to the symbolic and spiritual dimension of the ritual, it was possible to identify throughout the amateur championship that the actions performed by the players contributed to the structuring of the social positions in the group and in the amateur football field pontagrossense. In this way the acts of the rite were also acts of institution, through which one was notified about his "new" social position.

Keywords: Amateur Football; Ethnography; Culture; Ritual; Symbolic Power. 


\section{INTRODUÇÃO}

Investigar a maneira com que as crenças e, particularmente, os ritos reforçam os vínculos sociais entre os agentes, permite-nos interpretar o modo como a estrutura social de um grupo se fortalece e se perpetua através da simbolização ritual e mítica dos valores sociais que as compõem. ${ }^{1}$ Ou seja, no ritual se encontra a gênese das convicções dos agentes sociais de que as concepções legitimadas pelo grupo social (historicamente, socialmente e culturalmente) são verídicas e corretas. Para tanto, as disposições do rito e as motivações induzidas pelos símbolos sagrados nos agentes são organizadas estrategicamente.

Foi o que Geertz concluiu ao investigar as "Brigas de Galo" em Bali, pesquisa que o tornou referência na análise dos rituais. ${ }^{2}$ Daolio utilizou das discussões realizadas por Geertz, para interpretar as relações simbólicas e rituais do futebol brasileiro. ${ }^{3}$ Para tanto, Daolio estabelece paralelos entre o que significavam as Brigas de Galos em Bali, para os balineses e o que significa o Futebol no Brasil, para os brasileiros.

Em seu processo de análise o autor compara os galos de Bali aos jogadores de futebol brasileiros, os técnicos de futebol aos cuidadores dos galos, os patrocinadores dos clubes aos patrocinadores das rinhas e os torcedores aos apostadores paralelos, com o objetivo de analisar as relações sociais da torcida, estabelecendo apenas algumas aproximações com aqueles que o praticam. Assim, embora significativa para o olhar antropológico sobre as torcidas, a pesquisa de Daolio abre uma lacuna, qual seja a possibilidade de análise das práticas rituais e

\footnotetext{
${ }^{1}$ GEERTZ. O saber local.

${ }^{2}$ GEERTZ. A interpretação das culturas.

${ }^{3}$ Daolio realizou em uma de suas obras esta aproximação, enxergando no futebol, através da lente geertziana, conceitos estruturados pelo autor em Bali (quando estudava as rinhas de galo) - como a "duplicidade cruzada", expressa na impossibilidade de dissociação entre a explicação deste fenômeno como um fato da natureza ou fato da cultura, pois é justamente isto que define a briga de galos para Bali e o futebol para o Brasil, como entidades sociológicas. $\mathrm{O}$ segundo conceito possível de aplicação segundo o autor é o "brincar com o fogo" sem correr o risco de se queimar", o qual se refere aos sentimentos expressos pelos torcedores durante os jogos, embora alerte para a possibilidade de "queimaduras", referindo-se à violência entre as torcidas organizadas de futebol. Ver mais sobre esse assunto em: DAOLIO. Cultura: educação física e futebol.
} 
simbólicas dos jogadores, figuras centrais no processo de manutenção deste fenômeno cultural no Brasil.

Ao direcionar-se o olhar para a prática do futebol no Brasil, encontra-se na preparação para os jogos, nos vestiários dos clubes e em campo, nos momentos precedentes a partida, um dos rituais mais significativos e tradicionais. De acordo com Petrognani, ${ }^{4}$ o "fechamento" ou roda, como o autor nomeia o ritual, é uma prática específica do universo futebolístico brasileiro, que se consolidou como um dos elementos constituintes do habitus ${ }^{5}$ dos jogadores brasileiros. Por tratar-se de um elemento do habitus dos futebolistas, o fechamento pode ser observado nas diferentes interfaces do esporte no Brasil. ${ }^{6}$

Não obstante, para além da dimensão religiosa dos rituais, objeto de estudo de Petrognani, observou-se nos jogos do Mirante Esporte Clube, equipe de futebol pertencente ao campo futebolístico amador da cidade de Ponta Grossa, localizada no estado do Paraná-Brasil, o surgimento de uma economia simbólica, que ao longo das etapas do ritual e da competição atribuía aos jogadores da equipe, maior ou menor poder simbólico nas relações sociais. ${ }^{7}$

Neste viés, em virtude desta dinâmica espiritual, emocional, mas, sobretudo agregadora de capital simbólico, observada nos mais diversos rituais, Bourdieu

\footnotetext{
${ }^{4}$ PETROGNANI. Futebol e religião no Brasil: um estudo antropológico do "fechamento".

${ }^{5} \mathrm{O}$ habitus é um sistema de esquemas de produção de práticas e, ao mesmo tempo, um sistema de esquemas de percepção e apreciação destas práticas. Em ambos os casos, segundo o autor, a posição social em que estas práticas foram aprendidas é expressa pelos agentes. Desse modo, o habitus produz práticas e representações que "só são imediatamente percebidas enquanto tal por agentes que possuam o código, os esquemas classificatórios necessários para compreender-lhes o sentido social". Dessa forma, na relação entre a "capacidade de produzir práticas e obras classificáveis, além da capacidade de diferenciar e de apreciar essas práticas e esses produtos (gosto), é que se constitui o mundo social representado, ou seja, o espaço dos estilos de vida". Ver mais sobre esse assunto em: BOURDIEU. Coisas ditas, p. 158; BOURDIEU. A Distinção: crítica social do julgamento, p. 162. ${ }^{6}$ Damo apresenta uma possível divisão do futebol em quatro matrizes ou configurações, são elas: a) futebol profissional, que compreende-se e engloba os atores (jogadores, especialistas e torcedores) do futebol-espetáculo ou de alto rendimento; b) o futebol de bricolagem, revela-se através das peladas, dos rachas, fute e as demais designações locais; c) já o futebol comunitário, denomina-se em outros contextos como futebol de várzea, de bairro ou amador; d) a quarta configuração é o futebol escolar, que vincula-se às instituições escolares, com enfoque pedagógico. Ver mais sobre esse assunto em: DAMO. Monopólio estético e diversidade configuracional no futebol brasileiro.

${ }^{7}$ No decorrer da investigação, optou-se por trabalhar com nomes fictícios, como estratégia que visa preservar os sujeitos do clube no qual se realizou as observações in loco. A opção pela utilização de nomes fictícios foi em decorrência do grau de envolvimento estabelecido pelo pesquisador, ao ser aceito em várias camadas do grupo investigado, desta maneira sendo possível circular por diferentes subgrupos existentes dentro do próprio clube.
} 
opta por trabalhar com o termo "rito de instituição" ao invés de "rito de passagem", pois o autor infere que nestes processos não há apenas uma simples passagem, de menino para homem, por exemplo, mas existe um ganho de capital, convertido em poder simbólico ao agente social instituído. Portanto, o "fechamento" é, sobretudo, um rito de instituição. ${ }^{8}$

Destarte a presente investigação etnográfica objetiva analisar a função simbólica e instituinte das ações que compõe o ritual de preparação dos jogadores do Mirante E. C., para os jogos do campeonato amador de futebol da cidade de Ponta Grossa. Diante deste contexto, levanta-se o seguinte questionamento: quais os elementos que compõe o ritual de preparação dos jogadores para os jogos e qual a função sociocultural deste momento enquanto rito de instituição?

Ao referir-se aos fenômenos que podem ser considerados rituais, Peirano ressalta que não é possível antecipar a compreensão "do que é um ritual”, tornando-se necessária uma incursão in loco junto ao grupo social investigado portanto etnográfica -, pois se deve ter clareza de que o "outro" (nativo), não pensa ou age necessariamente com nós. Deste modo, mediante as necessidades para exploração do objeto foi que se estabeleceu o método de análise. ${ }^{9}$

\section{Procedimentos MEtodolóGicos}

No processo de aprendizagem e interpretação deste ritual, recorreu-se à etnografia, visto que o que se procura fazer em uma investigação etnográfica é compreender como os homens e mulheres tentam viver suas vidas. ${ }^{10}$ Esta compreensão se coloca através de um sistema entrelaçado de signos passíveis de interpretação, denominado cultura, dentro do qual os acontecimentos sociais, as instituições e as relações de poder precisam ser descritas densamente. ${ }^{11}$ Tendo

\footnotetext{
${ }^{8}$ BOURDIEU. A economia das trocas linguísticas: o que falar quem dizer.

9 PEIRANO. Rituais ontem e hoje.

${ }^{10}$ GEERTZ. Nova luz sobre a antropologia.

${ }^{11}$ GEERTZ. A interpretação das culturas.
} 
como referência as experiências de Geertz ${ }^{12}$ e Wacquant, ${ }^{13}$ na realização da presente investigação, superou-se as seguintes etapas:

Inicialmente estabeleceu-se o objeto e os sujeitos do estudo, estipulandose o campo futebolístico amador pontagrossense, pois nestes espaços ocorrem os campeonatos de maior legitimidade entre os jogadores da cidade. Durante a realização do estudo observou-se 26 clubes, nas diversas categorias do futebol amador em que estes participaram. Como o conhecimento preliminar sobre o objeto de estudo é essencial para traçar as primeiras estratégias de inserção ao campo, realizou-se um levantamento de artigos, ${ }^{14}$ dissertações, teses e livros, que abordam a questão do futebol amador em geral e do futebol amador no contexto da cidade de Ponta Grossa.

A terceira etapa a ser superada foi autorização legítima para adentrar no campo, facilitada através de uma visita dos pesquisadores a Liga de Futebol de Ponta Grossa (LFPG), entidade responsável pela organização e gerenciamento do futebol local, por meio da qual obteve-se os contatos dos clubes filiados. De posse destas informações realizou-se aleatoriamente uma ligação para o agente "responsável" pelo Mirante E. C., que foi o primeiro dentre os demais representantes a atender, a colocar-se a disposição para esclarecimento de dúvidas e a realizar convite para conhecer a estrutura e agentes envolvidos com o clube. Desta maneira, definiu-se o clube como o ponto de partida da investigação.

Efetivamente no campo de investigação, foram iniciadas as descrições iniciais (superficiais) do espaço social. Nesta etapa, realiza-se um primeiro processo de estruturação do mapa do campo, caracteriza-se pelas anotações do

${ }^{12}$ GEERTZ. O saber local; GEERTZ. A interpretação das culturas; GEERTZ. El antropologo como autor.

${ }^{13}$ WACQUANT. Corpo e alma: notas etnográficas de um aprendiz de boxe.

14 Sobre esse assunto, destaca os seguintes estudos: RIGO. Amizade, pertencimento e relações de poder no futebol de bairro. CUNHA et. al. Sport Club Barrense: memórias de um clube de futebol amador do município de São José do Norte/RS. MYSKIW; STIGGER. O futebol "de várzea" é "uma várzea"!? Etnografia da organização no circuito municipal de Porto Alegre. CAMPOS. Ligas municipais e Copa dos Rios de Seleções: integração do espaço amazonense através da centralidade subterrânea. OLIVEIRA. Entre a várzea e o profissional: sobre um campeonato de futebol amador. RIBEIRO. Futebol ponta-grossense: recortes da história. Mais recentemente. FREITAS JUNIOR; OLIVEIRA; LINHARES. O Mirante Esporte Clube: um estudo etnográfico do processo de aprendizagem e reprodução do gosto pela prática futebolística amadora na cidade de Ponta Grossa-Paraná (2013-2017). FREITAS JUNIOR; OLIVEIRA; GABRIEL. Interdependências estabelecidas na configuração futebolística amadora pontagrossense. 
máximo de informações possíveis, muitas delas ainda desconexas, mas potencialmente importantes para análises futuras. Para o armazenamento das informações provenientes destes encontros, utilizou-se o diário de campo (DC), devido a quantidade de informações que o pesquisador será exposto.

Partindo dos conceitos de "estar ali" e "estar aqui", descritos por Geertz, a materialização do DC fez-se dentro e fora de campo. ${ }^{15}$ Além do tradicional caderno, utilizou-se aplicativos para anotações e gravações de áudio do smartphone, devido à praticidade de seu uso e por se tratar de um objeto extremamente familiar para os agentes do campo. Entendeu-se que estes procedimentos causariam menos estranhamento, principalmente se comparados à utilização de um gravador tradicional ou de um caderno. A utilização destes recursos tecnológicos aliada a habilidade etnográfica desenvolvida ao longo de anos in loco, justifica a descrição integral de falas dos agentes, uma vez que estas eram anotadas quase que simultaneamente. A segunda etapa de construção do DC consistiu-se na escuta e posterior transcrição do áudio, em seguida a construção de um relatório complementar aliando as gravações e anotações realizadas in loco.

É importante destacar que todas as gravações realizadas durante as rodas de sociabilidade, foram autorizadas pelos participantes, que assinaram o Termo de Consentimento Livre e Esclarecido (TCLE). ${ }^{16}$ Deste modo, respeitou-se em todas as etapas do estudo a dignidade, a liberdade e a autonomia dos agentes sociais investigados, conforme exposto na Resolução no 466, de 12 de dezembro de 2012. Ressalta-se também que o estudo foi aprovado pelo Comitê de Ética e Pesquisa da Faculdade Sant'Ana, conforme designação da Plataforma Brasil, sob o número do Certificado de Apresentação para Apreciação Ética (CAAE): 66013317.8.0000.5694 e número do Parecer: 2.005.549.

\footnotetext{
${ }^{15}$ GEERTZ. El antropologo como autor.

${ }^{16}$ Deste modo foram "sujeitos diretos" do estudo, os jogadores que passaram por este clube entre os anos de 2014 a 2017, bem como os membros da diretoria e demais agentes envolvidos com as atividades do clube, totalizando 87 pessoas. Como o clube enfrentava a cada rodada diferentes equipes, estima-se que o universo total de agentes observados de forma indireta no campo ultrapassou a marca de 1.000 indivíduos. Ressalta-se que os 87 sujeitos diretos e os demais agentes citados no estudo, considerados em um primeiro momento como indiretos, mesmo aqui identificados com nomes fictícios, assinaram o Termo de Consentimento Livre e Esclarecido (TCLE).
} 
Não obstante, para que as descrições fossem ricas em sentido e significado, considera-se que o processo de aceitabilidade ou "ser aceito" pelo grupo social estudado, é parte fundamental da investigação (juntamente com a capacidade construir descrições densas). Quanto ao ser aceito, isso pode se estabelecer em longo, médio prazo ou até mesmo logo nos primeiros contatos do pesquisador com o grupo estudado. Visto que esta questão é relativa ao grupo (o qual pode ser mais ou menos acessível), bem como à postura do investigador (que pode dispor de maior ou menor facilidade, artifícios e estratégias para tornar esta aproximação possível). Todo este processo é muito mais complexo que uma definição temporal estabelecida aprioristicamente.

Deste modo, a baliza temporal, cabe destacar que o estudo foi desenvolvido entre os anos de 2014 a 2017. Neste tipo de análise o contato prévio com o tema, a autorização e aproximação com o grupo social investigado, a realização das primeiras descrições, a aceitação, para então a construção de descrições "densas", são etapas que se diferenciam de pesquisador para pesquisador, transformando o tempo em uma "variável dinâmica" em que a permanência in loco não pode ser definida antecipadamente. ${ }^{17}$

No decorrer deste processo, acompanhou-se os jogos do Campeonato Amador Divisão Especial (jogadores acima de 15 anos) e do Campeonato Amador Máster (jogadores acima de 35 anos). Estas partidas são realizadas em vários campos da cidade de Ponta Grossa e região, ocorrendo em sua grande maioria aos domingos pela manhã, característica que impossibilitou a observação de mais de uma partida por rodada (ou por semana). Partindo do pressuposto de que a profundidade da observação é a essência da investigação etnográfica, optou-se por acompanhar todas as partidas do Mirante E. C. e estabelecer-se através dele o olhar para os demais clubes, verificando-se assim as lógicas comuns e as lógicas que os diferenciam.

Além das partidas oficiais, acompanhou-se os jogadores em seus espaços de socialização e confraternização (antes e após os jogos), nos amistosos, nos jogos treino, nas peladas, realizadas aos sábados à tarde, feriados ou domingos pela

17 OLIVEIRA. Redescobrindo o sentido do jogo: um estudo etnográfico do processo de aprendizagem da cultura futebolística no mirante esporte clube em Ponta Grossa-Paraná (2013-2017). 
manhã, quando não havia jogo do campeonato amador. Também nos fizemos presentes nas festividades em datas comemorativas (aniversário do clube) ou para arrecadação de fundos, em multidões para realização de pequenas reformas, como pintura dos muros, troca de portas, construção de pisos e rampas e reuniões da diretoria do Mirante E. C. (no ano de 2017).

Nesse processo analítico, após a primeira saída in loco realizada no dia 19 de junho de 2014, permanecendo no campo rigorosamente durante todas as semanas até o dia 15 de outubro de 2017, totalizando aproximadamente 180 saídas a campo. Com tempo médio de permanência in loco de 5 horas, passou-se mais de 900 horas acompanhando o Mirante E. C.

Deste modo, após a autorização para inserção in loco e superada as camadas de aceitabilidade, iniciou-se efetivamente a construção das descrições densas. Esta adjetivação efetiva-se quando os pesquisadores são capazes de interpretar o ponto de vista dos próprios membros do grupo social investigado, através da vivência e da observação destas práticas oriundas de processos históricos, sociais e culturais. ${ }^{18}$ Ao passo que as descrições capturem os "detalhes, contextos, emoções e as nuances do relacionamento social a fim de evocar o 'sentimento' de uma cena e não apenas seus atributos superficiais". 19

Paralelamente ao processo de observação e estruturação do DC, realizouse a interpretação e a análise do material empírico proveniente das saídas a campo. Neste processo analítico a organização dos dados ocorreu de forma manual, considerara-se como fundamental no estabelecimento das categorias de análise, a frequência e a relevância das ações e práticas simbólicas observadas.

\section{RESULTADOS E DISCUSSÕES}

Ao longo das observações, percebeu-se um cenário semelhando ao descrito por Geertz ao dissertar sobre a função simbólica da religião no ethos de um grupo. ${ }^{20}$ No Mirante Esporte Clube os símbolos do futebol funcionavam como sintetizadores

\footnotetext{
${ }_{18}^{18}$ BOUMARD. O lugar da etnografia nas epistemologias construtivistas.

${ }^{19}$ ANGROSINO. Etnografia e observação participante, p. 32-33.

${ }^{20}$ GEERTZ. A interpretação das culturas.
} 
das disposições de agir e pensar do grupo, ou seja, sua "visão de mundo". A camiseta do clube, o calçar as chuteiras, o pisar no gramado com o pé direito primeiro ou o "nome do Pai" feito antes da entrada em campo, como se fosse necessário pedir permissão para adentrar no espaço, constituíam-se como símbolos e ações simbólicas necessárias neste espaço social. Deste modo, para o grupo de jogadores estas ações tornam-se intelectualmente razoáveis, pois representam um tipo de vida adaptado as visões de mundo, "enquanto essa visão de mundo torna-se emocionalmente convincente por ser apresentada como uma imagem de um estado de coisas verdadeiro, especialmente bem-arrumado para acomodar tal tipo de vida". ${ }^{21}$

Neste sentido, o "fechamento" ou "roda", de acordo com Petrognani, é parte integrante da cultura esportiva brasileira, "uma prática imprescindível ao futebol brasileiro justamente porque é a expressão simbólica de uma bricolagem religiosa própria do ser brasileiro". ${ }^{22}$ Tão significativa é esta prática para os agentes sociais que a executam, que estes acreditam na influência do ritual no bom ou mau desempenho em campo.

0 autor observou que o principal ato desta ritualização se encontrava no vestiário, um espaço dificilmente "pesquisável", pois não basta apenas uma autorização legítima para observação, torna-se necessário também o entendimento por parte do grupo de que a presença do pesquisador não irá interferir negativamente na dinâmica sagrada do ritual. Neste cenário, o fato de compor a equipe do Mirante E. C. na partida derradeira da primeira fase do Campeonato Amador Divisão Especial de 2016, ${ }^{23}$ permitiu-me o acesso ao vestiário e um lugar na disposição do ritual. É importante destacar que essa resistência não

${ }^{21}$ GEERTZ. A interpretação das culturas, p. 66-67.

${ }_{22}$ PETROGNANI. Futebol e religião no Brasil: um estudo antropológico do "fechamento", p. 199.

${ }^{23}$ Embora não planejada, a oportunidade de jogar pelo clube surgiu em um jogo válido pela última rodada da primeira fase do Campeonato Amador Divisão Especial de 2016. A participação do Mirante E. C. nesta edição, assim como nas competições anteriores, cercou-se de dificuldades, desde 0 apoio de patrocinadores até a inscrição de jogadores para 0 campeonato, conforme já mencionado. Nesta edição da competição, o clube contou com a presença de somente um goleiro, o qual após uma discussão com um companheiro de equipe foi expulso. Como eu havia acompanhado as peladas e jogos do clube (embora nunca tivesse jogado com eles), seu Tião pegou meus documentos para registrar-me na LFPG, assim, disputei a rodada final do Campeonato. Após este jogo, consegui um lugar no vestiário e um espaço na dinâmica do ritual. 
se resume a pesquisadores; os familiares, por exemplo, também não possuem espaço nos vestiários, com exceção dos meninos, quando crianças. ${ }^{24}$

No vestiário, espaço geográfico, mas, sobretudo simbólico, que comporta as discussões, os acordos, as concordâncias, as estratégias e tudo aquilo que deve ser intransitável em conversas exteriores, as equipes encontram o momento ideal para alinharem seus desejos pessoais em torno de uma meta coletiva. Para algumas equipes, que compõe o campo futebolístico amador de Ponta Grossa, esta meta deve ser compreendida como a conquista do título amador, por exemplo. Para outras, representar bem suas comunidades já é suficiente, caso dos "Clubes de Vila". No Mirante E. C., tornava-se latente a busca pela construção de uma identidade coletiva em torno do clube.

Para melhor compreender os objetivos das equipes amadoras de futebol de Ponta Grossa, Oliveira constrói uma tipologia dos clubes a partir de suas características centrais, são eles: 1) Clubes de Vila - aqueles que surgiram a partir de diferentes agentes em torno de uma localidade específica de Ponta Grossa, os quais possuem em seus nomes referências às vilas que representam, além de um sentimento de pertencimento dos jogadores com a localidade e dos moradores da vila com o clube; 2) Clubes Sociais/Associativos - aqueles que surgiram a partir de diferentes agentes em torno de um Clube Social (sem fins lucrativos) ou Associativos (com mensalistas), com exceção da questão financeira, estes clubes possuem uma organização semelhante, com formação de diretoria, eleições para presidente e etc; 3) Clubes Empresa - aqueles que surgiram a partir de diferentes agentes em torno de uma empresa, assim sendo, possuem como nome da equipe o nome da empresa, estes também recebem apoio financeiro e estrutural da empresa, para manutenção das atividades do grupo; 4) Clubes Visitantes - clubes

${ }^{24}$ Os meninos eram iniciados nas práticas futebolísticas através de seus pais, dessa forma, eles experimentavam diferentes situações, por meio das quais seria possível incorporar as competências valorizadas pelo grupo. Nesse processo, os filhos menores, com idades entre quatro e dez anos, aproximadamente, eram expostos a uma infinidade de estímulos, sem grandes restrições, como: jogar bola nos espaços externos do campo; entrar e jogar no campo, nos momentos precedentes, no intervalo e após o término das partidas; entrar nos vestiários com os pais (espaço bastante restrito,); e ficar no banco de reservas ou nos espaços destinados à imprensa durante as partidas. Todas essas práticas seriam desautorizadas, se partissem de outras pessoas ou até mesmo em se tratando de meninos mais velhos, porém, os pais compreendiam esta faixa etária, como a fase ideal para a aprendizagem do gosto pelo futebol. 
de cidades vizinhas que participam da competição na cidade. Por serem de "fora" de Ponta Grossa, foram identificados como visitantes. ${ }^{25}$

No mesmo estudo o autor realiza uma subdivisão dos jogadores que disputam os campeonatos amadores de futebol de Ponta Grossa, a partir de suas características em quatro tipos, são eles: 1) Aqueles que jogam devido à identidade com o clube - estes jogadores eram o núcleo central das equipes, pois estabeleciam relações de longa duração e acumulavam várias funções no clube, ou seja, além de jogadores eram também diretores, responsáveis por patrocínios e o que mais fosse necessário. Outra característica marcante era a presença de familiares nos jogos do clube e o desejo deste jogador de associar seu nome ao clube. 2) Aqueles que jogam devido às relações de amizade e rodas de sociabilidade - estes jogadores encontravam-se mais próximos de relações duradouras com o clube, mas a ligação emocional se estabelecia primeiramente com o grupo de amizade, assim os resultados e condições de jogo não eram centrais, mas sim a sociabilidade. Em virtude desta situação a possibilidades de entrarem nos clubes Ortodoxos eram reduzidas. 3) Aqueles que jogam devido ao amor pelo futebol - para estes jogadores a confraternização não era central, ela deveria ser merecida. Além disso o "amor" levava-os a compor várias equipes, deste modo jogar bem era essencial. 4) Aqueles que jogam devido aos benefícios ou remunerações - em alguns casos a remuneração destes jogadores era velada, para não afetar o equilíbrio da equipe. Na maioria dos casos se tratavam de ex-jogadores profissionais, portanto receber significava ser reconhecido, o que era condição fundamental para permanecer no campo.

A partir destas tipologias de clubes e jogadores, emergiam as relações de aproximação e distanciamento. Não obstante, para atingir este nível de coletividade a coesão do grupo torna-se fundamental, o que significava encontrar equilíbrio nas relações de poder, uma tarefa complexa se consideradas as diferentes tipologias de jogadores, pois, embora um determinado tipo de jogador predomine de acordo com a classificação dos clubes (Vila, Social/Associativo, Empresa e Visitante), o elenco completo era composto por mais de um destes tipos.

${ }^{25}$ OLIVEIRA. Redescobrindo o sentido do jogo: um estudo etnográfico do processo de aprendizagem da cultura futebolística no mirante esporte clube em Ponta Grossa-Paraná (2013-2017). 
Desse modo, o ritual de preparação para os jogos torna-se o espaço e o momento no qual as identidades devem ser forjadas e transformadas. ${ }^{26}$

O horário de chegada dos jogadores no estádio, antes dos jogos, geralmente era definido pelo técnico do Mirante E. C. no início da competição, porém, esta baliza temporal sofria alterações ao longo do campeonato. Durante o período observado, o técnico solicitava que os jogadores chegassem com aproximadamente uma hora de antecedência, entretanto, alegava incluir neste horário entre 15 e 20 minutos a mais do que considerava necessário, estabelecendo, deste modo, uma margem de tolerância. Geralmente, com aproximadamente 30 minutos para início da partida, os jogadores dirigiam-se ao vestiário.

Embora o tempo cronológico fosse o parâmetro de marcação utilizado, este ritual não segue rigidamente os horários pré-estabelecidos. Há a possibilidade de todo o grupo chegar próximo dos 30 minutos restantes, às vezes até menos, ou então, chegarem com mais de uma hora de antecedência. Para os agentes, este é o primeiro dos indicativos a ser observado, o qual possuirá ligação com o desfecho da partida. Quando se tratam de casos isolados, os atrasos (chegar quando o grupo já está no vestiário, ou seja, com menos de 30 minutos de antecedência) não possuem relevância, com exceção de algumas cobranças pontuais, mas quando uma grande parte do grupo passa a chegar cada vez mais tarde, esta atitude pode ser compreendida como um termômetro, um medidor de comprometimento e envolvimento grupal. Em alguns casos, potencialmente problemático para a execução do ritual. Acredita-se que, inconscientemente, para os jogadores, o período de espera até que todos estejam presentes, para então deslocarem-se ao vestiário, torna-se um momento importante para o estreitamento das relações.

Quando os jogadores chegavam ao estádio, um dos primeiros temas dos diálogos era a família. Iniciavam com um "Tudo bem?", “Tudo em ordem”, "Tudo certo" e na sequência dialogavam sobre a presença ou ausência de filhos, filhas ou esposas. A partir deste ponto, as rotinas da semana eram compartilhadas com o grupo, fosse ela boa (aniversários, idas a cinemas, circo) ou ruim (problemas escolares, médicos, discussões no relacionamento). Com o decorrer do tempo, mais

${ }^{26}$ CANAL; QUINTILLA. Du mec au joueur, p. 1-11. 
jogadores do clube chegavam, porém, dificilmente formava-se mais de uma roda de conversa e, quando se formava, era rapidamente diluída pela roda maior.

Tendo como ponto de partida as reflexões de Petrognani, pode-se dizer que está roda de conversa se construiu como o primeiro ato deste ritual de preparação para os jogos. Pois, ao compartilharem com o grupo suas experiências vividas ao longo da semana, estes jogadores se reconheciam com os demais companheiros de time, respeitando-se não somente pelo desempenho em campo, mas pelos esforços realizados para estarem com o grupo. ${ }^{27}$ Como se pode observar no diálogo entre os reservas da equipe do Mirante, em uma partida do Amador Máster versus o Clube Empresa "A", na sexta-feira 21 de abril de 2017, no estádio dos adversários...

Um dos reservas diz: “- Cara, o Ademir não está jogando nada hoje, não ganha uma ali no meio, está morto o homem". Na sequência outro jogador o responde: “- Você não ouviu ele falando antes do jogo? Que teve que trabalhar a noite inteira. Trabalhou a tarde e depois fez o turno da noite também, ele trabalha de segurança". Outro reserva complementou: "- Ele só veio hoje porque o Marquinhos não podia vir, senão não viria nenhum dos volantes que jogam pela esquerda. Veio direto para o jogo, só passou em casa pegar a chuteira e tomar um café". Após os comentários o jogador reserva que fez a crítica diz com entonação amena: "- Então está explicado", e em seguida grita "Vamos Ademir", em tom de incentivo. ${ }^{28}$

Tanto nesta partida, quanto em outros encontros, os diálogos precedentes aos jogos nas rodas evitaram possíveis conflitos, devido a sua função agregadora de identificações. Neste sentido, Petrognani salienta que a "dimensão simbólica mais evidente que absorve o(s) "fechamento(s)" é de participar da construção e consolidação do laço social, ressaltando o sentimento de pertencimento que permite a um grupo de se reconhecer como pertencente a uma mesma comunidade". ${ }^{29}$

Nesse processo, destaca-se, também, a eficácia dos sacrifícios - seja abrir não de horas extras no trabalho; faltar alguma festividade em família devido aos jogos; mas principalmente não faltar ao jogo por dores leves ou desconfortos, são

\footnotetext{
${ }^{27}$ PETROGNANI. Futebol e religião no Brasil: um estudo antropológico do "fechamento". ${ }^{28}$ DC, 21 de abril de 2017.

${ }^{29}$ PETROGNANI. Futebol e religião no Brasil: um estudo antropológico do "fechamento", p. 191.
} 
deliberações convertidas em status, em legitimidade perante o grupo e o campo, deste modo são encaradas pelos jogadores como deveres.

Na manhã do dia 02 de julho de 2017, por volta das 9:30 horas da manhã, antes de um dos jogos treino preparatório para disputar a competição amadora na categoria principal, eu conversava com o zagueiro Paulo sobre as competições dos clubes que estavam em suas retas finais, quando este queixou-se de dores nas costas, devido a uma dividida "maldosa" (segundo ele) de um adversário, durante uma partida válida pelas quartas de final de um deste campeonatos de clubes associativos, em que ele e outros jogadores do Mirante haviam formado um time. Ele contou-me que no dia seguinte ao jogo, não conseguia levantar-se da cama sem apoiar-se nos móveis próximos, para ir ao trabalho, caminhando com muita dificuldade. Ao explicar aos colegas de trabalho suas limitações no exercício das funções, e principalmente o motivo pelo qual estava daquela forma, "trombada maldosa", os colegas compreenderam a situação e fizeram por ele as atividades que ele não conseguia. No dia seguinte sem grandes melhoras, ele foi até um massagista, que "colocou o nervo ciático no lugar", porém recomendou uma semana de descanso, sem atividades físicas. Entretanto, na quanta feira Paulo burlou as recomendações para jogar as semifinais da competição no clube. Queixando-se novamente de dores nos dias seguintes (quinta, sexta e sábado), porém embora bastante limitado nos movimentos, estava disposto a treinar pela manhã no Mirante e ir disputar a tarde a final de tal competição. Perguntado o porquê de tantos "sacrifícios"? Ele alegou que na sua idade (38 anos) não é possível mais jogar sem dores, e que se fosse esperar uma condição física ideal não jogaria mais. Assim, o sacrifício corporal só alimentava e fortalecia a alma e o espírito de jogador, ainda mais devido à campanha de sua equipe no campeonato. "- Independente do campeonato que for eu não abandono meu time em uma semifinal ou final. Eles precisam de mim, contam comigo, eu devo esse esforço a eles, porque confiam em mim". ${ }^{30}$

No decorrer desta conversa, vários jogadores do Mirante pararam o que faziam e passaram a ouvi-la, os relatos eram vistos como certo "heroísmo", vindo de alguém que o grupo poderia contar sempre. Enquanto Paulo relatava sua experiência dolorosa, tornava-se cada vez mais visível o quanto ele acreditava no que dizia, ou seja, Paulo estava convencido de um "dever moral" para com o grupo, que exigia dele "sacrifícios" e mesmo existindo riscos de complicações à saúde, seria necessário corrê-los pelo grupo. Principalmente, nos jogos "absorventes", como as disputas de "mata-mata" entre alguns clubes.

${ }^{30}$ DC, dia 02 de julho de 2017. 
Tal atitude pode ser compreendida também, através da perspectiva do "lazer sério" cunhada por Stebbins. O conceito emergiu ao longo de seus estudos sobre lazer, em decorrência da necessidade de se explicar porque alguns praticantes de atividades de lazer, destinavam um tempo significativo de suas rotinas cotidianas objetivando desenvolver e aperfeiçoar as habilidades necessárias para melhorar seu rendimento e potencializar as chances de recebimento de recompensas através da prática de lazer. Através das palavras do autor, "Every serious leisure career both frames and is framed by the continuous search for these rewards, a search that takes months, and in many pursuits, years before the participant consistently finds deep fulfillment in his or her amateur, hobbyist, or volunteer role". 31

De acordo com Geertz, a estratégia dos balineses para tornar-se um embate interessante ou "absorvente", era fazer com que a aposta central fosse a maior possível; os galos os mais semelhantes e os melhores possíveis; e o resultado o mais imprevisível dentro das possibilidades. No entanto, "O que torna a briga de galos balinesa absorvente não é o dinheiro em si, mas o que o dinheiro faz acontecer, e quanto mais dinheiro, mais acontece: a migração da hierarquia de status balinesa para o corpo da briga de galos". 32

Dentre as partidas observadas, o jogo de domingo, dia 11 de junho de 2017, foi um dos jogos "absorventes" para os agentes envolvidos com o Mirante E. C., pois há anos o clube não chegava às semifinais do campeonato amador de futebol pontagrossense. Mesmo não se tratando da categoria de maior prestígio, vencer esta partida e chegar à final da competição apresentava-se como um desejo compartilhado entre o grupo, principalmente devido ao adversário, o Clube Social Ortodoxo "B".

$\mathrm{Na}$ fase de grupos do campeonato, o Mirante E. C. enfrentaria o Clube Social Ortodoxo "B", dia 12 de março de 2017, na "casa" do adversário, porém, o jogo não ocorreu, pois, ao sair do túnel que dava acesso ao campo, os jogadores do Mirante E. C. não avistaram os adversários, que ainda se encontravam no vestiário. O atraso não foi tolerado pelos jogadores do Mirante E. C. que, logo após passarem-

${ }^{31}$ STEBBINS. Serious Leisure: A Perspective for Our Time, p. 22.

${ }^{32}$ GEERTZ. A interpretação das culturas, p. 201. 
se os 15 minutos de tolerância, pediram ao árbitro que apitasse o início da partida, vencendo deste modo, por W. O. Tão logo o árbitro da partida decretou a vitória do Mirante, os adversários saíram do túnel de acesso ao campo do estádio do Clube Social Ortodoxo "B". Sabendo do ocorrido, houve o início de tumulto e, mesmo com a vitória, os jogadores do Mirante foram ironizados pelos adversários, sendo chamados de "bundões" e "medrosos", por aceitarem uma vitória sem jogo devido ao "medo" e "certeza" da derrota em campo. ${ }^{33}$

Se faltava para os adversários uma prova de coragem, a vitória do Mirante E. C. por 1x0, no jogo de ida da semifinal, na casa do Clube Social Ortodoxo "B" foi apontada pelos jogadores do Mirante, como o acontecimento que legitimava a força deste grupo. Assim, estes acontecimentos construíram um cenário ainda mais incerto e tenso, para o jogo de volta, no estádio do Mirante.

Nos dias precedentes ao jogo de volta, era visível a ansiedade dos jogadores ao pensarem e falarem sobre a partida que estava por vir. No grupo de whatsapp, as mensagens seguiam certa padronização, os tradicionais mêmes jocosos compartilhados nos domingos e quartas-feiras, durante e após as rodadas do Campeonato Brasileiro, perderam espaço para as mensagens de motivação ou frases e fotos religiosas.

$\mathrm{Na}$ manhã do jogo, cheguei ao estádio do Mirante E. C. às 9 horas. Ao aproximar-me das rodas de conversa que ali se formavam, percebi um silêncio incomum à rotina de gozações. Embora sempre houvesse a concentração, esta partida era diferenciada. Os diálogos giravam em torno de possíveis estratégias táticas, reforçando a dimensão séria da prática, ${ }^{34}$ além das frases de apoio como: "no jogo passado você deitou em cima dele" ou "lá você não deixou ele se criar". 0 clima modificava-se apenas quando alguns veteranos realizavam tentativas de descontração, as quais surtiam certo efeito, despertando alguns risos, porém sempre controlados. 35

\footnotetext{
${ }^{33}$ DC, 12 de março de 2017.

${ }^{34}$ STEBBINS. Serious Leisure: A Perspective for Our Time.

${ }^{35}$ Ao dirigir a palavra a um agente do campo, com idade elevada, ou citá-lo nas rodas de conversa, não se deve utilizar os substantivos "velho" ou "idoso". Mesmo que este agente demonstre claramente traços de envelhecimento, a ancoragem do velho a características negativas torna seu uso ofensivo. Nesse viés, a utilização da palavra idoso comporta a mesma carga simbólica, porém de forma polida. Destarte, deve-se utilizar o substantivo "veterano", o
} 
Como nas partidas anteriores, às 9 horas e 15 minutos todos os jogadores já se encontravam presentes no estádio. Desse modo, iniciou-se o segundo momento deste ritual, com a entrada dos jogadores no vestiário. 0 sentido completo desta entrada ocorre somente nos jogos em casa, devido à disposição dos jogadores nos espaços do vestiário; entretanto, independente do estádio, este tornava-se o momento da "transformação", do eu social, do peladeiro, para jogador de futebol.

Neste processo, a troca da vestimenta era bastante simbólica. Em seus locais preestabelecidos, os jogadores faziam deste ato um momento individual, de concentração e silêncio. Semelhante aos jogadores de rendimento, não se observou um jogador que chegasse uniformizado ou de chuteiras calçadas para o jogo, pois a troca ela elemento significante do rito. Destarte, ao guardarem suas roupas casuais em suas bolsas, as representações sobre si no cotidiano as acompanhavam, bem como suas fraquezas e seus estigmas.

Para tanto, cada detalhe do rito era significativo, por exemplo, uma plaquinha pequena com o nome dos jogadores mais antigos no clube e a existência de um gancho no vestiário para cada jogador, no qual era pendurado os meiões o calção e por fim a camisa que este utilizaria no jogo. Esta preparação prévia, realizada por um dos auxiliares técnicos, que "imita" em certa medida o altíssimo rendimento, fazia toda diferença para os jogadores. Era visível nos seus olhares, o deleite de adentrarem no vestiário e encontrarem o espaço preparado, com seu uniforme no local simbólico que ocupam, bem como o desejo ou satisfação de ter um local nomeado.

Da mesma forma, ao enfaixarem os tornozelos (alguns), vestirem os calções, calçarem os meiões e as chuteiras, e por fim, vestirem as camisas do clube, estes jogadores transformavam-se, adquirindo uma "força sobrenatural", vendo-se como "guerreiros" (expressão utilizada pelos próprios nativos, para referir-se ao grupo, durante os discursos performáticos preparatórios, para as partidas, principalmente nos jogos absorventes), capazes de superar qualquer situação ou adversário.

qual tem a função de demarcar uma distinção clara entre os agentes do campo, entre "o que é ser velho" e "o que é ser veterano". Pois no segundo caso, a ancoragem está associada às experiências de vida, posto de alguém pertencente ao campo por um longo período. 
Dentro da dinâmica da ritualização, as ações seguiam sempre uma ordem padronizada. Enquanto os jogadores retiravam suas vestes, o técnico Eduardo e seu auxiliar Kleber, realizavam algumas orientações, bem como definiam a equipe titular para a partida. Já os jogadores, após vestirem as camisas, levantavam-se dos seus lugares, circulando inquietamente pelo vestiário, dirigindo-se ao banheiro, molhando o rosto e cabeça na pia, cumprimentando outros companheiros com frases de apoio. Neste momento, o clima no vestiário transformou-se, as frases ditas em tom de voz moderado tornaram-se gritos, cada vez mais altos, até que o último homem estivesse devidamente uniformizado.

No Mirante E. C., o último a vestir-se era sempre o goleiro Gustavo, capitão do grupo e "responsável" pelo discurso de indução dos companheiros de equipe ao estado de intensa emoção. ${ }^{36}$ Como se pode observar na descrição do DC a seguir, nos momentos precedentes à disputa do jogo de volta da semifinal do Campeonato Amador Máster contra a equipe do Clube Social Ortodoxo "B":

Após estarem devidamente uniformizados, Gustavo pede para que todos os jogadores abracem-se formando uma grande roda (desconfigurada devido ao espaço pequeno do vestiário do clube). Com o grupo em formação Gustavo inicia seu discurso: - Eu quero dar os parabéns pra vocês, principalmente na hora da oração lá, aquele dia (jogo de ida da semifinal entre Mirante E. C. versus Clube Social Ortodoxo "B", dia 04 de junho de 2017). Eu nunca vi um grupo assim, parecia um exército indo pra guerra, um exército que queria vencer. Cara, chego até a me arrepiar na hora da oração, a força de vontade que vocês estavam aquele dia de jogar bola, eu já vi na hora da oração. Nós mostramos, graças a Deus, que vocês têm muita garra [...] Tá certo que nós já fizemos a primeira parte lá, mas não vai resolver nada se nós não fizer hoje aqui. Não adianta nada. Nós fizemos o que tinha que ser feito lá, mas se aqui na nossa casa se nós não fizer, não vai resolver. Nós temos o regulamento embaixo do braço, mas isso não quer dizer nada. Se nós entrar lá incomodado, nós vamos tomar um chocolate. Agora se cada um de vocês fizer o que fizeram domingo passado moçada, não tem ninguém que ganha de nós (com ênfase e tom de voz elevado e elevando-o gradativamente). Não tem. Porque vocês jogaram com muita raça. Foram guerreiros. Já na oração eu senti que era um exército que tava indo pra guerra [...] Gustavo aumenta o tom de vós: - Nós somos uma família. Se perder vai todo mundo perder junto, mas nós vamos continuar com esse grupo. Por quê? Porque esse grupo se tornou uma família (seguido por várias manifestações de concordância). Perca ou ganhe. Eu vejo um brilho no rosto de vocês. Então eu quero que vocês joguem o jogo da vida de vocês, é o último jogo moçada, último jogo, 1 a 0 não quer dizer nada,

\footnotetext{
${ }^{36}$ PETROGNANI. Futebol e religião no Brasil: um estudo antropológico do "fechamento".
} 
nada, nada, (esqueçam a final piazada, disse um dos jogadores) esqueça, que nós temos vantagem, vamos jogar por nós, vamos por a bunda no chão, se ver que não vai pegar, você vai pegar sim, se por a bunda no chão vai pegar. Ganha aquele cara que vai até o último minuto e não desiste. Foi uma bola que o Dedé pegou e perdeu lá no domingo, mas ele acreditou cara, ele perdeu, mas ele acreditou. É isso que eu quero de vocês, acreditem, acreditem em cada um de vocês moçada, o que eles falaram (referindo-se a gozações realizadas por alguns jogadores adversários), vocês tem que levar no coração e na chuteira de vocês, que vocês são muito mais que qualquer outro jogador. Então vamos lá. Pai nosso que estás no céu... Ave Maria cheia de graça... Finalizando o momento de oração com a recitação do código: Um por todos! (Gustavo) Todos por um! (demais jogadores e comissão técnica) Um por todos! Todos por um! Um por todos! Todos por um! 1, 2, 3, Mirante! 37

Segundo Petrognani, a predicação, esta forma de discurso "profético" que ocorre na "roda", deve ser performática. Ou seja, o que importa de fato, não é o conteúdo das palavras, mas sim a intensidade com que ela é proferida e a posição social daquele que a profere dentro do grupo. ${ }^{38}$ Como salienta Petrognani, o importante é a indução dos demais companheiros de equipe a estados de intensa emoção. Neste contexto, o conteúdo da predicação foi bastante relevante, principalmente os relacionados à família e a Deus, os quais possuem a capacidade de despertar a efervescência do grupo e "transformar um evento ordinário em algo extraordinário, transcendente, induzindo nos seus ouvintes a presença de uma força que os antropólogos associam com a irrupção do sagrado". 39

Segundo Bourdieu, um enunciado performativo está condenado ao fracasso, se pronunciado por um agente destituído de "poder" para pronunciá-lo. ${ }^{40}$ Não obstante, o contrário é verdadeiro, ou seja, quando um agente instituído de poder simbólico discursa, o efeito deste é notório entre os demais agentes. Situação que se constatou ao presenciar os discursos performáticos de Gustavo no vestiário do Mirante E. C. nos dias de jogos. É importante destacar que ele era o capitão da equipe, um posto simbólico dentro da cultura futebolística, o fomentador de um discurso competente. ${ }^{41}$

\footnotetext{
${ }^{37}$ DC, dia 11 de junho de 2017.

${ }^{38}$ BOURDIEU. A economia das trocas linguísticas: o que falar quem dizer.

${ }^{39}$ PETROGNANI. Futebol e religião no Brasil: um estudo antropológico do "fechamento", p. 196.

${ }^{40}$ BOURDIEU. A economia das trocas linguísticas: o que falar quem dizer.

${ }^{41}$ CHAUI. Cultura e democracia: o discurso competente e outras falas.
} 
Neste processo de consagração e legitimação da fala, o ritual é o acontecimento capaz de tornar o arbitrário como algo legítimo e até mesmo natural. Não obstante, um ritual só tem efeito, se o ato de nomeação for realizado por um agente social autorizado a realiza-lo e, também, se as disposições pré-estabelecidas e institucionalizadas de um ritual válido forem respeitosamente cumpridas. ${ }^{42}$

Após uma oração estremecedora, em um volume alto, com um sentimento de entrega gigantesco, ouviram-se inúmeros gritos de palavras de apoio e palavrões. Na sequência das práticas, o técnico Eduardo abriu a porta do vestiário do Mirante, neste momento o silêncio fez-se presente, ao posso que era possível ouvir o barulho das travas das chuteiras tocando o solo, durante o trajeto deles do vestiário até a entrada em campo. Neste momento, iniciava-se o processo de reestabelecimento da ordem, completando a sequência tripartida descrita por Petrognani.

Encerrada a partida, ao longo da competição de 2017, os jogadores, dirigentes e familiares (filhos e filhas), realizavam o último ato do rito. Segundo a mesma lógica das descrições de Petrognani, este "fechamento" caracterizava-se pela reflexão, pelos elogios "instituintes", “a oração do Pai Nosso é executada para agradecerem por tudo o que aconteceu durante a partida. A elocução é lenta; não se trata mais de incentivar estados de ânimos alterados, mas, pelo contrário, de restabelecer uma ordem, encerrando as atividades". 43

Neste último ato, geralmente, os agentes instituídos (alguns jogadores, técnico, auxiliares e algumas vezes os veteranos) proferem elogios àqueles jogadores que se destacaram no decorrer da partida. Seja por um gol feito, um passe que deu origem a uma boa jogada, pela marcação feita sobre um jogador de destaque da equipe adversária ou até mesmo por um carrinho visando evitar a saída da bola. Na grande maioria das vezes, o elogio não ocorre pelo êxito, mas pela tentativa, pelo esforço.

Desse modo, o elogio ou a crítica "em público", perante todo o grupo, torna-se uma ação agregadora de capital simbólico que, somada a outras ações, fundamenta a instituição ou destituição social de um agente por outro, que

\footnotetext{
${ }^{42}$ BOURDIEU. A economia das trocas linguísticas: o que falar quem dizer.

${ }^{43}$ PETROGNANI. Futebol e religião no Brasil: um estudo antropológico do "fechamento", p. 189.
} 
[...] agindo em seu próprio nome ou em nome de um grupo mais ou menos importante numérica e socialmente, quer transmitir a alguém o significado de que ele possui uma dada qualidade, querendo ao mesmo tempo cobrar de seu interlocutor que se comporte em conformidade com a essência social que lhe é assim atribuída.44

Vale ressaltar que a instituição através da roda, não se efetiva somente com um elogio solto e não ocorre a todo momento para todos, visto que o cenário deve ser propício e uma série de critérios precisam sem cumpridos, como a autoridade daquele que institui e o reconhecimento do instituído perante seu grupo.

\section{CONSIDERAÇõES FINAIS}

A presente investigação objetivou analisar a função simbólica e instituinte das ações que compõe o ritual de preparação dos jogadores do Mirante E. C., para os jogos do campeonato amador de futebol da cidade de Ponta Grossa. Ao longo da pesquisa, o que descreveu-se nos diários de campo, foi uma transformação das representações dos jogadores sobre o "eu social" e o "eu jogador", ou seja, ao adentrarem nos vestiários para se prepararem para os jogos, estes agentes "transformavam-se" em uma espécie de idealização de si mesmo, ancorando seus gestos, práticas e discursos aos de um jogador de futebol profissional. Deste modo, a representação que os jogadores compartilhavam de si naquele espaço e tempo, não era a de peladeiros, atletas de fim de semana, mas jogadores de futebol com todo o simbolismo que esta posição social carrega no Brasil.

Geertz, ajuda-nos refletir sobre esta questão ao argumentar que "Num ritual, o mundo vivido e o mundo imaginado fundem-se sob a mediação de um único conjunto de formas simbólicas, tornando-se um mundo único e produzindo aquela transformação idiossincrática no sentido de realidade". 45 Desse modo, ressalta-se a importância de um olhar atento a todas as sutilezas expressas nas práticas e nos discursos do grupo social investigado. Pois, como se pode observar no ritual de preparação para os jogos, até mesmo o mais singelo gesto, possui um

\footnotetext{
${ }^{44}$ BOURDIEU. A economia das trocas linguísticas: o que falar quem dizer, p. 82.

${ }^{45}$ GEERTZ. A interpretação das culturas, p. 82.
} 
sentido e um significado, agregador de poder simbólico a um agente dentro do grupo e do campo futebolístico amador pontagrossense.

Assim como já apontaram Damo ${ }^{46}$ e Petrognani ${ }^{47}$ em outros estudos, corrobora-se com a afirmativa de que a significância do ritual é tamanha, que reforça a tese da necessidade de um aquecimento de espírito, para além do convencional aquecimento corporal. Vale ressaltar também, que o time de futebol do Mirante Esporte Clube acreditava que um ritual eficaz, ou seja, uma preparação que cumprisse todas as etapas do rito, contribuiria para o bom desempenho da equipe em campo, podendo inclusive influenciar no resultado de uma partida.

Não obstante, para além da dimensão simbólica e espiritual do ritual, foi possível identificar ao longo do campeonato amador, que as ações executadas pelos jogadores do Mirante Esporte Clube, contribuíam para a estruturação das posições sociais no grupo e no campo futebolístico amador pontagrossense.

Deste modo os atos do rito eram também atos de instituição, através dos quais alguém é notificado sobre a sua "nova" posição. No contexto do Mirante, para os jogadores mais jovens, chegados recentemente ao clube, significava passar a fazer parte da "Família", "Ser Mirante”. Já para os agentes pertencentes à família, o próximo passo viria em longo prazo, com suas instituições ao posto de "veterano".

\section{REFERÊNCIAS}

ANGROSINO, Michael. Etnografia e observação participante. Porto Alegre: Artmet, 2009.

BOUMARD, Patrick. O lugar da etnografia nas epistemologias construtivistas. Londrina, Revista de Psicologia Social e Institucional, v.1, n.2, p. 1-6, 1999.

BOURDIEU, Pierre. A Distinção: crítica social do julgamento. Daniela Kein, Gilheme J. F. Teixeira, Porto Alegre: Zouk, 2008a.

${ }^{46}$ DAMO. Do dom à profissão: a formação de futebolistas no Brasil e na França.

${ }^{47}$ PETROGNANI. Futebol e religião no Brasil: um estudo antropológico do "fechamento". 
BOURDIEU, Pierre. A Economia das Trocas Linguísticas: O que Falar Quem Dizer. Sérgio Miceli. $2^{\underline{a}}$ edição. São Paulo: Editora da Universidade de São Paulo, 1998.

BOURDIEU, Pierre. Coisas ditas. Trad. Cássia R. da Silveira e Denise Moreno Pegorim, São Paulo: Brasiliense, 2004.

BOURDIEU, Pierre. O poder simbólico. Trad. Fernando Tomaz. $5^{a}$ edição, Rio de Janeiro: Bertrand Brasil, 2002.

BOURDIEU, Pierre. Razões práticas: Sobre a teoria da ação. Trad. Mariza Correa, 9a edição, Campinas: Papirus, $2008 \mathrm{~b}$.

CAMPOS, Fernando Rosseto Gallego. Ligas municipais e Copa dos Rios de Seleções: integração do espaço amazonense através da centralidade subterrânea. Curitiba, Revista Ra'E Ga, v. 35, p. 288-313, 2015.

CANAL, Jean-Luc; QUINTILLA Caroline. Du mec au joueur. Marseille, Corps et Culture, v. 1, n. 4, 1999, p. 1-11.

CHAUI, Marilena de Sousa. Cultura e democracia: o discurso competente e outras falas. 12ª edição, São Paulo: Cortez, 2007.

CUNHA, Leonardo Costa da; et. al. Sport Club Barrense: memórias de um clube de futebol amador do município de São José do Norte/RS. Marechal Cândido Rondon, Espaço Plural, v. 14, n. 29, p. 67-89, 2013.

DAMO, Arlei Sander. Monopólio estético e diversidade configuracional no futebol brasileiro. Porto Alegre, Movimento, v. 9, n. 2, p. 129-156, 2003.

DAMO, Arlei Sander. Do dom à profissão: a formação de futebolistas no Brasil e na França. Tese (Doutorado em Antropologia Social) - Programa de PósGraduação em Antropologia Social, Universidade Federal do Rio Grande do Sul, Porto Alegre, 2005.

DAOLIO, Jocimar. Cultura: educação física e futebol. Campinas: Editora da Unicamp, Campinas $3^{\underline{a}}$ edição, 2006.

FREITAS JUNIOR, Miguel Archanjo de; OLIVEIRA, Edilson de; LINHARES, Wendell Luiz. O Mirante Esporte Clube: um estudo etnográfico do processo de aprendizagem e reprodução do gosto pela prática futebolística amadora na cidade de Ponta Grossa-Paraná (2013-2017). Mosaico, Rio de Janeiro, v. 9, n. 14, p. 302-320, jul. 2018.

FREITAS JUNIOR, Miguel Archanjo de; OLIVEIRA, Edilson de; GABRIEL, Bruno José. Interdependências estabelecidas na configuração futebolística amadora pontagrossense: uma análise etnográfica (2013-2016). Pensar a Prática, Goiânia, v. 21, n. 3, p. 577-587, 2018.

GEERTZ, Clifford. A interpretação das culturas. Rio de Janeiro: LTC, 2008.

GEERTZ, Clifford. El antropologo como autor. Barcelona: Paidos, 2010.

GEERTZ, Clifford. $O$ saber local: novos ensaios em antropologia interpretativa. Petrópolis: Editora Vozes, 2003b. 
GEERTZ, Clifford. Nova luz sobre a antropologia. Rio de Janeiro: Jorge Zahar, 2001.

LIGA DE FUTEBOL DE PONTA GROSSA. Regulamento do Campeonato de Futebol Amador de Ponta Grossa - 2016. Liga de Futebol de Ponta Grossa, Ponta Grossa, 2016.

MYSKIW, Mauro; STIGGER, Marco Paulo. O futebol "de várzea" é "uma várzea"!? Etnografia da organização no circuito municipal de Porto Alegre. Movimento, Porto Alegre, v. 20, n. 2, p. 445-469, 2014.

OLIVEIRA, Allan de Paula. Entre a várzea e o profissional: sobre um campeonato de futebol amador. Marechal Cândido Rondon, Espaço Plural, v. 14, n. 29, p. 114-139, 2013.

OLIVEIRA, Edilson de. Redescobrindo o sentido do jogo: um estudo etnográfico do processo de aprendizagem da cultura futebolística no mirante esporte clube em Ponta Grossa-Paraná (2013-2017). Dissertação (Mestrado em Ciências Sociais Aplicadas), UEPG, Ponta Grossa, 2018.

PEIRANO, Mariza. Rituais ontem e hoje. Rio de Janeiro: Zahar, 2003.

PETROGNANI, Claude. Futebol e religião no Brasil: um estudo antropológico do "fechamento". 2016, 236 f. Tese (Doutorado em Antropologia Social) Programa de PósGraduação em Antropologia Social, Universidade Federal do Rio Grande do Sul, 2016.

RIBEIRO JUNIOR, José Cação. Futebol Ponta-Grossense: Recortes da História. Ponta Grossa: Editora UEPG, 2004.

RIGO, Luiz Carlos. Amizade, pertencimento e relações de poder no futebol de bairro. Pensar a Prática, Goiânia, v. 10, n. 1, p. 83-98, 2007.

STEBBINS, Robert A. Serious Leisure: A Perspective for Our Time. New York: Routledge, 2017.

WACQUANT, Loic. Corpo e Alma: Notas etnográficas de um aprendiz de boxe. Rio de Janeiro: Relume Dumará, 2002.

Recebido para publicação em: 12 out. 2018. Aprovado em: 21 mar. 2019. 